\title{
Convergent Shelf Flow at CaPe Mendocino
}

\author{
By The NCCCS Group: \\ B.A. Magnell, N.A. Bray, C.D. Winant, \\ C.L. Greengrove, J. Largier, J.F. Borchardt, \\ R.L. Bernstein, C.E. Dorman
}

\begin{abstract}
Observations taken during the course of the Northern California Coastal Circulation Study (NCCCS) pilot experiment from March through August of 1987 show that shelf currents often converge near Cape Mendocino, resulting in offshore transport. This convergence occasionally, though not always, is accompanied by convergence in the large-scale winds. A cyclonic eddy, roughly $20 \mathrm{~km}$ in diameter, is commonly found on the south side of the Cape, where, on the shelf, the average currents are directed to the north. The water temperature in this area is colder than that observed north of the Cape, where the average current is to the south. Correlation between currents and the local vind near the Cape is lower than expected from previous results obtained during the Coastal Ocean Dynamics Experiment (CODE) conducted in the same general region, though farther south, along a straight section of the coast. Similarly. temperature and wind fluctuations at a given location are less correlated than they were during CODE.

These patterns are not those expected for typical coastal upwelling areas. The coincidence of coldest surface temperatures and persistent northward shelfflow' is particularly intriguing, as is the lack of correlation between currents and wind. Interactions between the shelf flow and the California Current, vartations in the large-scale structure of the wind, the influence of polew'ard-traveling shelf waves, and the role of Cape Mendocino in determining flow' in the atmosphere as well as in the ocean are discussed as possible causes of the observed convergence. Some of these effects mav be responsible for enhanced upwelling near other capes and headlands.
\end{abstract}

$\mathrm{F}$

OR A DISTANCE of more than $1000 \mathrm{~km}$, from Point Conception to Puget Sound, the western coast of the United States may be described as a series of broad embayments, each a few hundred kilometers long, and separated by prominent capes. The shelf is narrow, and within each embayment the coast is fairly straight. The classical view of shelf circulation along this coast is one of two-dimensional coastal upwelling: northwesterly alongshore winds drive offshore currents at the surface, and the surface layers are replenished by cold, nutrient-rich water from depth. Equatorward transport is geostrophically balanced by the cross-shelf pressure gradient thus established.

Extensive observations taken during the Coastal Ocean Dynamics Experiment (CODE) in the

B.A. Magnell, C.L. Greengrove, and J.F. Borchardt, EG\&G Washington Analytical Services Center. Inc.. 237 Riverview Avenue, West Newton, MA 02154; N.A. Bray, C.D. Winant and J.Largier. Scripps Institution of Oceanography. Center for Coastal Studies, A-009, La Jolla. CA 92093; R.L. Bernstein, SeaSpace, 3655 Nobel Drive. Suite 160. San Diego. CA 92122; C.E. Dorman, San Diego State University, Department of Geological Sciences, San Diego, CA 92182. upwelling seasons of 1981 and 1982 led to an improved understanding of the dynamics of the upwelling process. CODE was conducted along the straight stretch of coastline just south of Point Arena, an area where alongshore variability in the flow was limited. The present study, in contrast, examines the larger scale circulation, which is distinctly threedimensional, with alongshore variability dominated by the capes and headlands that define the different embayments.

Cape Mendocino is the dominant headland of the northern California coast, and appears to have an even more profound effect on the circulation than other promontories of the region. The abrupt Mendocino Escarpment lies perpendicular to shore, rising. over a distance of a few kilometers, from a depth of $2000 \mathrm{~m}$ north of the Cape to a plateau of $500 \mathrm{~m}$ depth west of the Cape. The shelf virtually disappears on the south side of the Cape, further interrupting the continuity of the alongshelf flow. An example of the complexity of structure about Cape Mendocino during the spring upwelling season is illustrated in Fig. 1. Winds and currents are superimposed on the seasurface temperature distribution during an episode of 


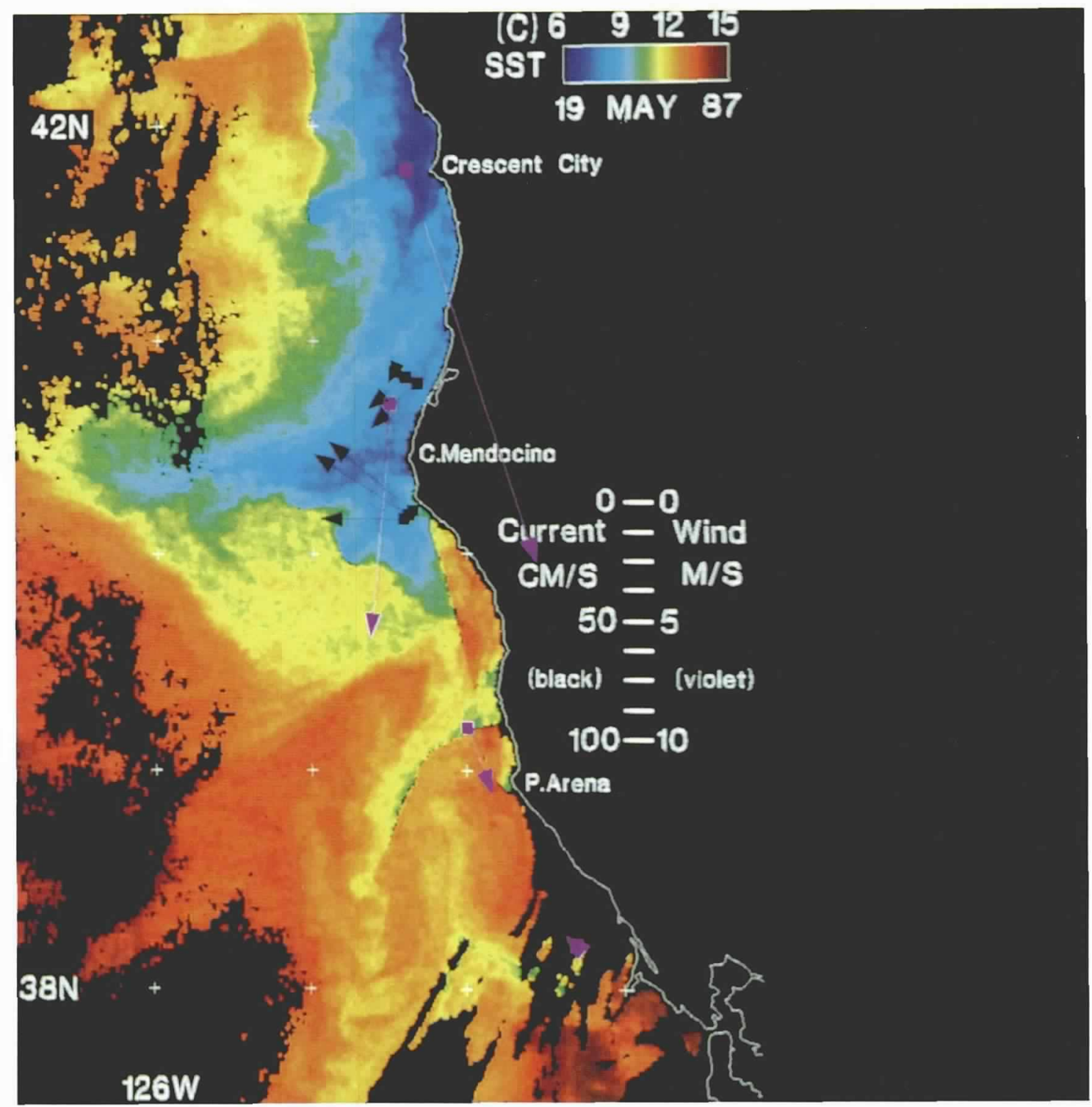

Fig. 1: AVHRR sea-surface temperature satellite image for May 19, 1987. Wind and near-surface current velocity vectors are superimposed (violet and black arrows, respectively), from low-passed time series sampled at the time of satellite overpass.

convergence in the shelf flow. Associated with apparent offshelf flow is a cold plume extending 300 km west of the Cape.

Wind forcing is not uniform along the coast of northern California. During the spring and summer upwelling season, the boundary between the subtropical Pacific high pressure system and the more variable, storm-dominated north Pacific occurs near $40^{\circ} \mathrm{N}$ (Halliwell and Allen, 1987), which also happens to be the latitude of Cape Mendocino. Locally, the coastal mountain range often channels the wind alongshore, and changes in the orientation of the coast can result in pronounced alongshore gradients in atmospheric forcing. For example, mountainous terrain shelters the shelf south of Cape Mendocino from the prevailing northwesterly winds.

With the exception of CODE, direct observations of circulation in the northern California coastal region are sparse. The NCCCS, a 5-year physical oceanography program supported by the Minerals Management Service of the U.S. Department of the Interior, is intended to describe the shelf and slope circulation over the region from San Francisco to the Oregon border, with particular emphasis on nearsurface currents. The NCCCS seeks to characterize the circulation statistically and dynamically, using moored current meters, drifters, and hydrographic surveys, supported by tide gauge, meteorological and satellite AVHRR (Advanced Very High Resolution Radiometer) observations. The program is comprised of a pilot experiment, focused on Cape Mendocino and carried out from March through August of 1987, and full-scale main experiment, conducted from March 1988 to November of 1989. Other observational programs conducted in the same region at various times during NCCCS included CTZ (Coastal Transition Zone), SMILE (Surface MixedLayer Experiment), and a United States Geological 


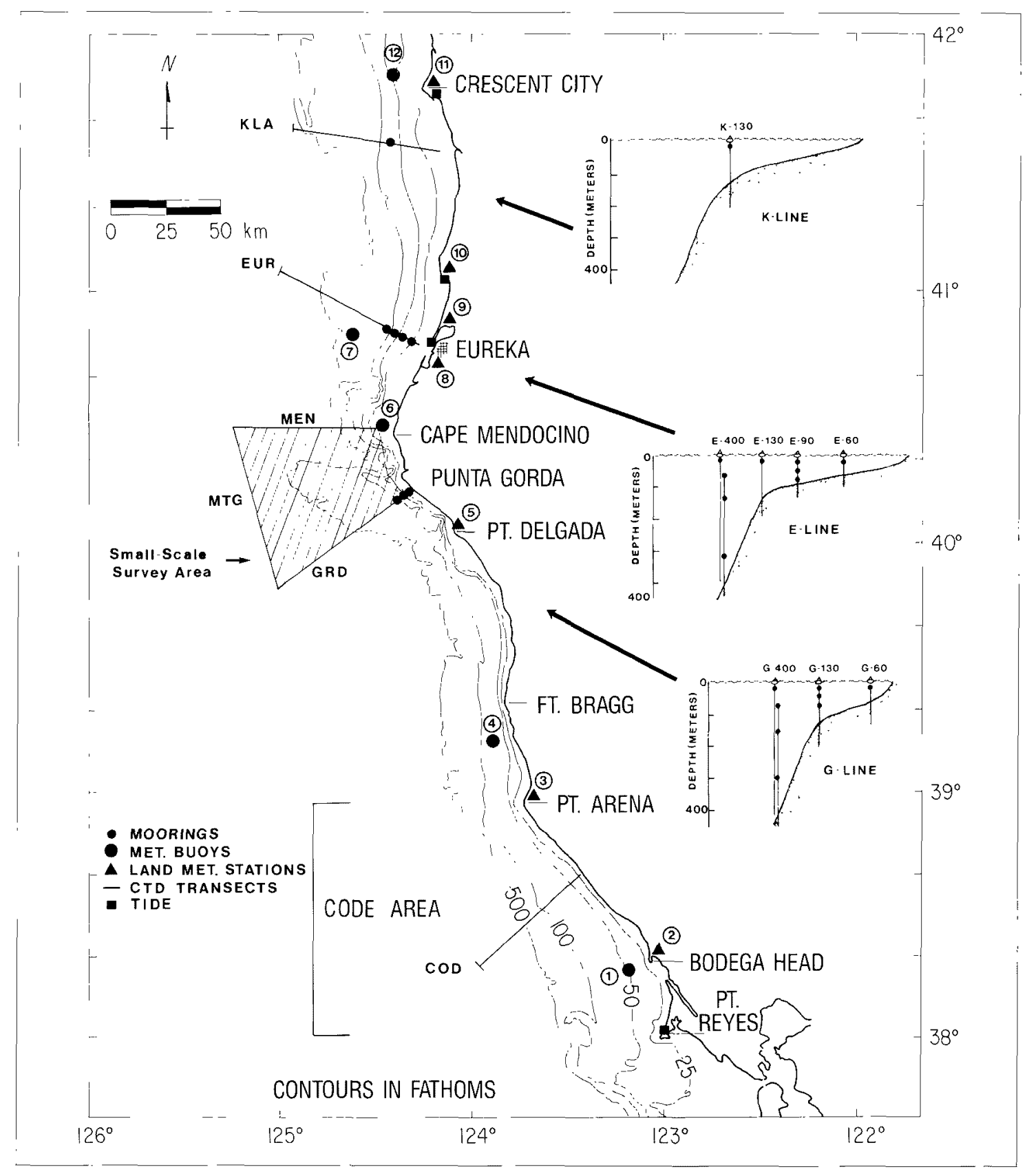

Fig. 2: The Northern California Coastal Circulation Study region. Solid lines depict CTD transects; hatched area is the small-scale survey; small dots are current meter moorings; large dots are NDBC meteorological buoys; triangles are land-based meteorological stations: and squares are NOS tide gauge stations. Buoy wind stations are:\#1,Bodega, 45013:\#4.Pt. Arena, 46014;\#6. Blunts Reef.46030;\#7.Eel River, 46022; and \#12, Pt. St. George. 46027. Coastal wind stations are: \#2, Bodega Head; \#3. Pt. Arena C-MAN; \#5, Shelter Cove (EG\&G): \#8, Humboldt Bay; \#9, Arcata Airport; \#10, Trinidad Head; and \#11, Crescent City Airport. The insets to the right of the figure are cross-sections showing the configuration of each mooring line.

Service (USGS) study in the Gulf of the Farallons. The Pilot Experiment

NCCCS field measurements began in March 1987 with a 5-month pilot program concentrated near Cape Mendocino (Fig. 2). The CODE results suggested an experiment design based on cross-shelf transects. to resolve circulation patterns within each embayment and to identify major differences between embayments. Current meter and bottom pres- sure mooring transects were located on both sides of the Cape, at Eureka (the E-line), and Punta Gorda (the $\mathrm{G}$-line). One mooring was placed farther north in the Eel River embayment, near Crescent City (the Kline), to test the hypothesis that alongshelf variability occurs primarily between embayments, rather than within them. The pilot moored arrays extended from $60 \mathrm{~m}$ to $400 \mathrm{~m}$ water depth, with eighteen current meters and four bottom pressure recorders (see Fig. 


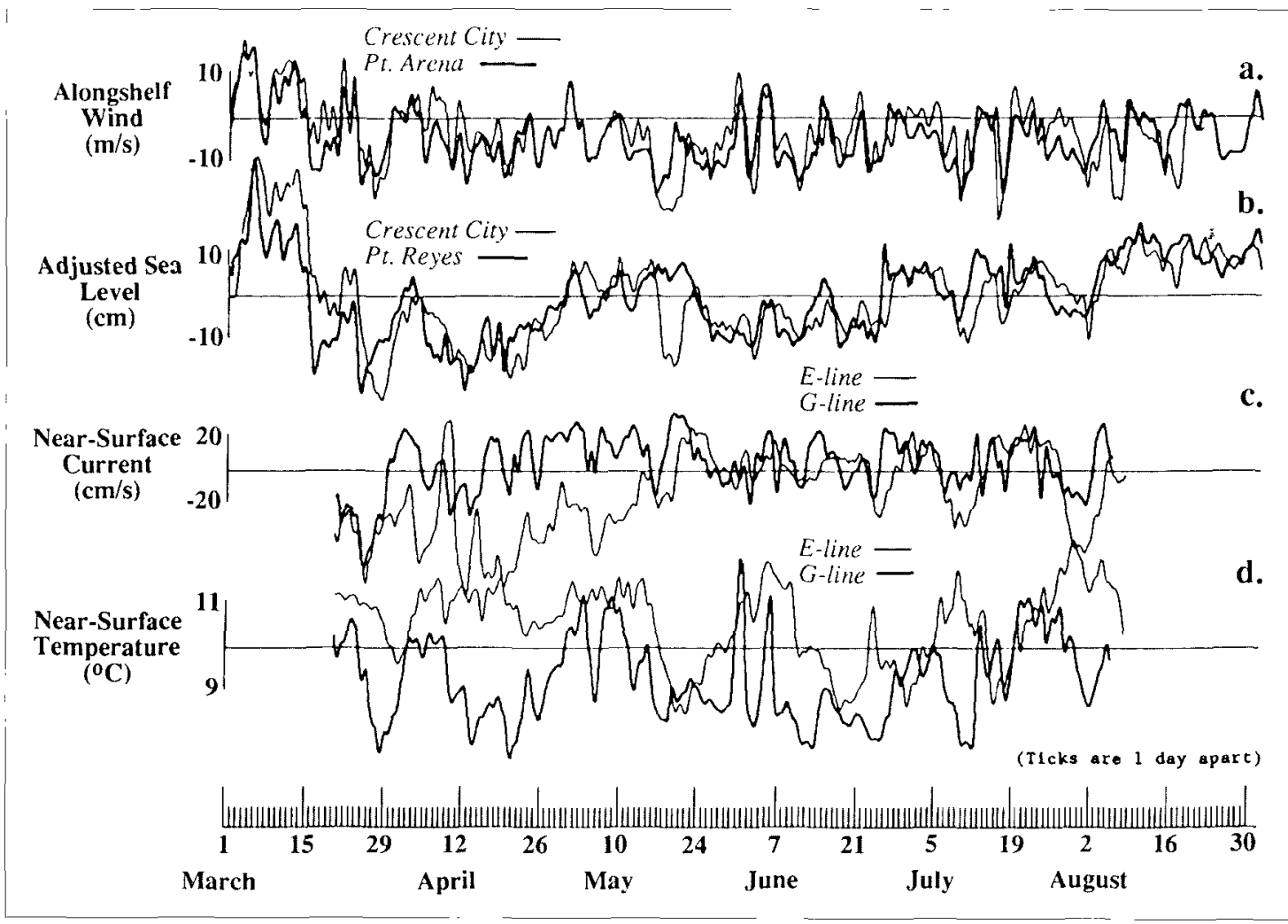

Fig. 3: Comparison of (a) low'passed wind. (b) adjusted sea level, (c) near-surface currents, and (d) temperature observations from north and south of Cape Mendocino during the pilot experiment.

2 insets). Surface flotation supported Vector Measuring Current Meters (VMCMs) on all shelf moorings and at depths shallower than $75 \mathrm{~m}$ on deeper moorings. Acoustic current meters and rotor/vane current meters were used with subsurface flotation at greater depths. Moored instruments were equipped with temperature sensors.

Hydrographic transects perpendicular to the coast were occupied at the five locations shown in Fig. 2 during cruises in March and August 1987. These transects extended $75 \mathrm{~km}$ offshore, with stations 5 to $10 \mathrm{~km}$ apart. Fig. 2 also shows a small-scale survey area near Cape Mendocino that was occupied on each cruise. Observations consisted of CTD (conductivity, temperature. depth) and XBT (expendable bathythermograph) profiles taken at roughly $5 \mathrm{~km}$ intervals, from which salinity and density are calculated. Approximately twenty-four drifters were deployed and tracked with aircraft during both cruise periods, typically for ten days with fixes obtained twice per day. Meteorological measurements from eight NDBC buoys on the California and Oregon shelf were combined with data from several shore stations to describe the wind field. Sea level time series from ganging stations along the entire northern Pacific coast were obtained from the National Ocean Survey. These observations are reported in Magnell et al. (1988) and discussed in Magnell et al. (1989).

\section{Principal Shelf Flow Patterns}

As an overview of the pilot experiment results. representative time series of wind, sea level, current and temperature from locations on either side of Cape Mendocino are shown in Fig. 3. Winds (Fig. 3a) were correlated north and south of the Cape, although frequently the wind speeds differed, and occasionally, winds were actually in opposite directions. Adjusted sea-level (ASL) observations from Crescent City and Point Reyes (Fig. 3b) are better correlated than the winds. Nevertheless, episodes of substantial alongshelf sea level gradient were observed, corresponding to periods when the wind was not uniform alongshore. In contrast, there is no significant correlation at any time lag between near-surface currents measured at mid-shelf on either side of the Cape (Fig. 3c). In fact, currents frequently converged at the Cape, although there were periods when flow was continuous around the Cape. Temperatures measured at the same locations as the currents (Fig. $3 d$ ) were not significantly correlated at any lag, either. Temperatures off Punta Gorda were usually colder than off Eureka, with a maximum difference of about $2{ }^{\circ} \mathrm{C}$ during April.

The overall lack of correlation alongshelf in current and temperature is in marked contrast to the CODE results (Winant et al., 1987), where moorings separated by an equivalent distance alongshore were highly correlated along that relatively straight section of coast. As can be seen in the time series of currents, there is a great deal of long-period (several month) variability that does not appear to be directly attributable to local winds. This low-frequency component of the flow was convergent, with shelf
There is no significant correlation at any time lag between nearsurface currents measured at mid-shelf on either side of the Cape 
This tendency for

currents to converge

at the Cape was

enhanced when

equatorward winds

were stronger north

of the Cape. currents flowing toward the Cape from both directions, particularly during April and May. Throughout the pilot program, this tendency for currents to converge at the Cape was enhanced when equatorward winds were stronger north of the Cape.

A striking example of this enhancement is the episode of upwelling-favorable winds that began simultaneously north and south of the Cape on May 14. The wind relaxed south of Cape Mendocino four days later, but continued to strengthen in the north. By May 19, wind speeds were in excess of $20 \mathrm{~m} / \mathrm{s}$ at Crescent City, but had decreased nearly to zero at the Pt. Arena buoy. At the same time, a large equatorward gradient in ASL (poleward pressure gradient) was established, in opposition to the direction of the wind stress. Currents south of the Cape reversed direction to poleward as the wind ceased, while currents north of the Cape continued to flow southward under the influence of the wind, resulting in intense convergence at the Cape. The satellite image of sea-surface temperature from May 19 shown in Fig. 1 corresponds to this period. Cold plumes like the one illustrated have been observed before in this region (Kelly, 1985). While in this case convergent shelf flow was coincident with convergence in the wind field, convergent currents were also observed during extended periods of uniform winds.

The overview time series of Fig. 3 may be summarized in terms of two main patterns of circulation near Cape Mendocino: one in which the shelf waters flow continuously around the Cape and a second pattern in which the flow converges at the Cape. These shelf flow patterns are reflected in sea surface temperature distributions: cold water is confined to the shelf and slope for uniform southward flow, and a cold plume extends west from the Cape during periods of convergent flow.

The time-averages of the currents shown in Fig. 3 were also convergent: equatorward at the E-line off Eureka and poleward at the G-line off Punta Gorda. This is surprising, since the period covered is the upwelling season, when the average currents are expected to be equatorward. Further, the coldest surface temperatures observed were at Punta Gorda, and were associated with poleward currents, different from classical upwelling. This time-averaged picture, however, does not provide much insight into how this circulation is established, what forces it, and how it is related to the wind. To address those questions, the moored instrument time series observations are examined statistically, and individual events, or periods comprised of a single flow pattern, are examined using the survey data.

Three episodes are used as examples here: uniformly southward flow that was observed during the first survey cruise (March 15-20); the period of strong convergence in late May; and the second survey cruise (August 1-6), when the flow was also convergent. The survey periods were chosen primarily because of the additional detail provided by the hydrographic and drifter observations, though differing flow patterns are represented. The May survey
Wind-Wind Coherence
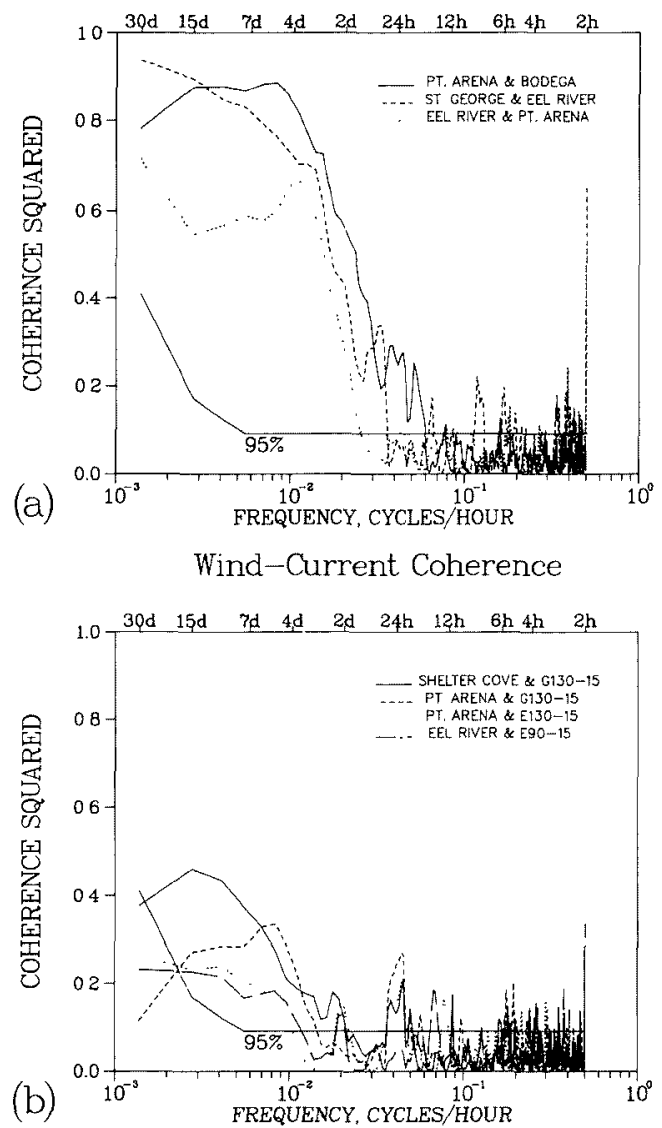

Current-Current Coherence

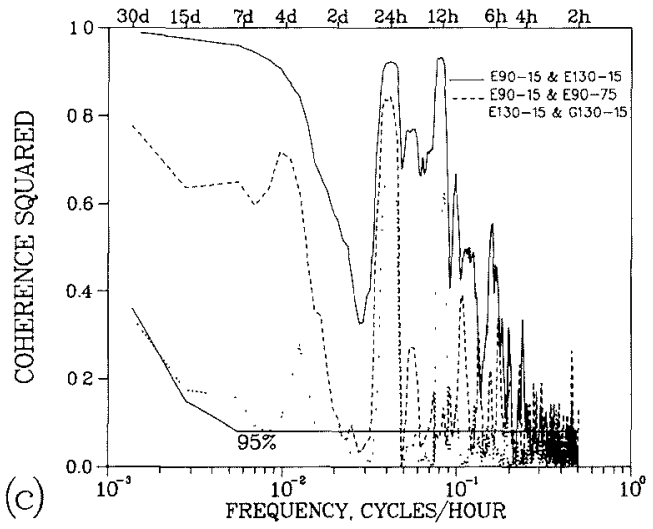

Fig. 4: Coherence squared of alongshore winds and currents during the pilot program, estimated using ensemble averages of 30-day Hanning-windowed segments, $50 \%$ overlapped, with additional frequency smoothing of up to seven points. The $95 \%$ confidence levelfor zero true coherence is labeled.Designations beginning with $E$ or $G$ refer to current meter observations (northand south of Cape Mendocino,respectively), and also give the water depth followed by instrument depth. Wind observations are designated by the name of the measurement station. See Fig. 2 for locations. 

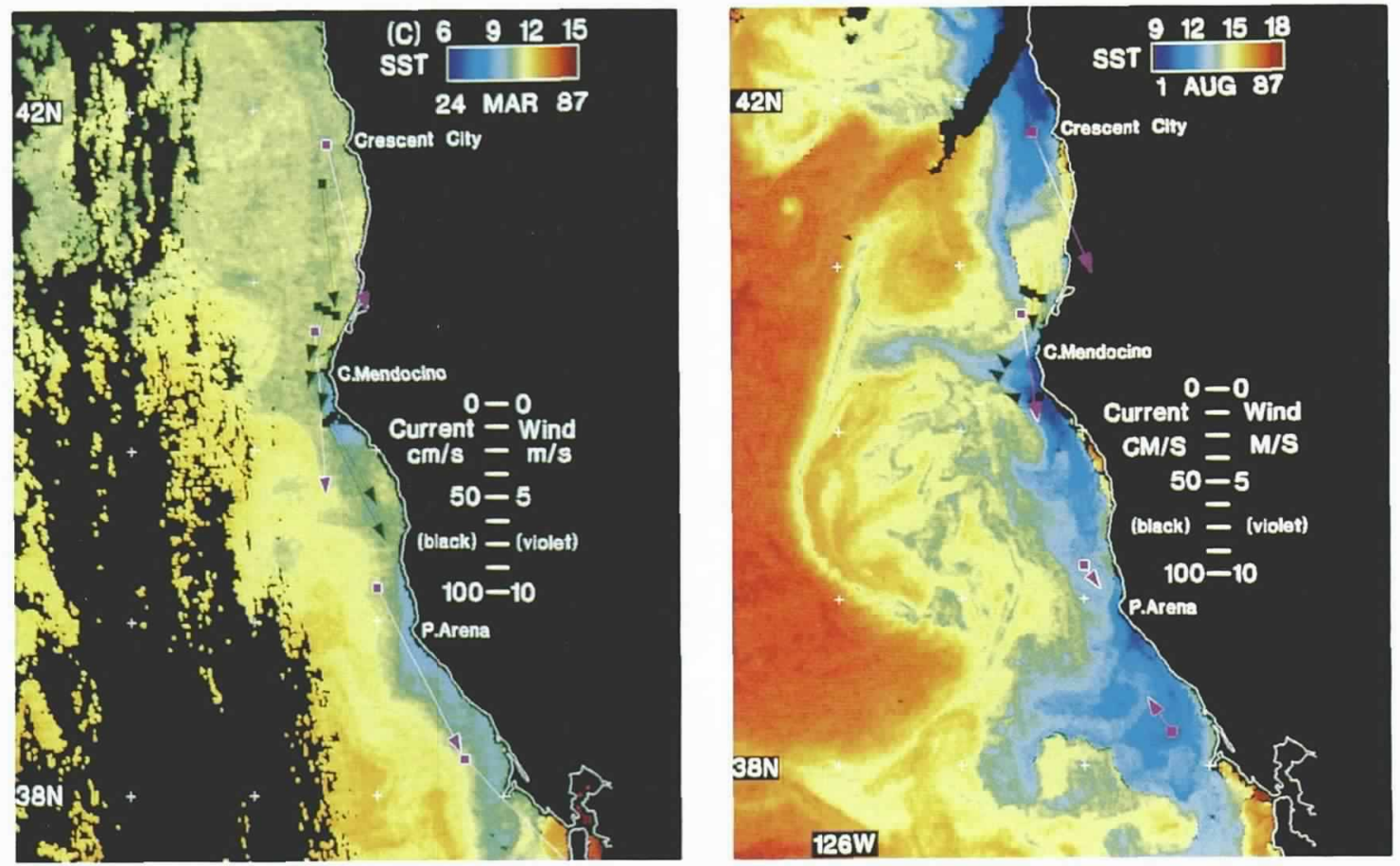

Fig. 7: AVHRR sea-surface temperature satellite images for March 24, 1987, (Fig. 7a, left) and for August 1, 1987 (Fig. 7b, right). Wind and near-surface current velocity vectors are superimposed (violet and black arrows, respectively), from low-passed time series sampled at the time of satellite overpass.

was chosen because of the strength of the shelf convergence, and because differences in the wind field may have been responsible for enhancing the difference in shelf currents north and south of the Cape.

\section{Moored Time Series}

The variation in frequency of different forcing mechanisms for shelf flow, such as tides, winds, and open ocean currents, suggests dividing the analysis into different frequency bands. Although not shown in the low-pass filtered series of Fig. 3, differences in current structure north and south of the Cape extend into tidal frequencies. At the E-line, north of the Cape, tidal currents are similar to those found in the CODE area: tidal energy is spread over a relatively wide band, and little coherence is found between currents and sea level at tidal frequencies (Rosenfeld and Beardsley, 1987). Along the Punta Gorda transect just south of the Cape, the tidal current energy appears as sharp peaks associated with tidal forcing frequencies, and there is a constant phase relationship between currents and sea level.

At frequencies associated with most of the wind field variability (2-20 days), the alongshelf component of wind is moderately to highly coherent between alongshelf-separated observations (Fig. 4a). This high coherence implies that wind fluctuations tend to co-vary in time, but does not preclude alongshelf gradients of wind stress, since the amplitude of the fluctuation is not necessarily uniform. There is only marginal coherence between local winds and currents north of the Cape (Fig. 4b). In contrast, currents south of the Cape are more strongly coherent with the local wind, though not as coherent as winds and currents measured during CODE. Consistent with this, near-surface currents on either side of the Cape are only marginally coherent (Fig. 4c), even in the wind-driven band. Currents are highly coherent across the shelf, and in the vertical to a lesser extent, on a given mooring transect (Fig. 4c).

The lowest frequency currents resolved by the observations (periods of months, not shown in Fig. 4) are also well correlated across the shelf and upper slope, from $60 \mathrm{~m}$ depth to $400 \mathrm{~m}$ depth, with comparable amplitudes along each transect. However, there were significant differences in the currents observed north and south of the Cape, as, for example, during the 2-month period in April and May when currents off Eureka were consistently southward at $20-40 \mathrm{~cm} / \mathrm{s}$ while south of the Cape currents were northward at $10-20 \mathrm{~cm} / \mathrm{s}$ (Fig. 3c).

\section{Hydrographic and Drifter Surveys}

Surveys conducted during March and August provide resolution of smaller scale features found between the E-line and G-line mooring transects, as well as information about the vertical structure of the velocity field offshore of the deepest moorings. A concise view of the horizontal structure of the baroclinic flow field in the vicinity of the Cape is contained in the dynamic height contours as illustrated in Fig. 5 (p. 10). Velocity vectors derived from the movement of radio-tracked surface drifters are superimposed on the dynamic height maps. Although both types of observations required several 


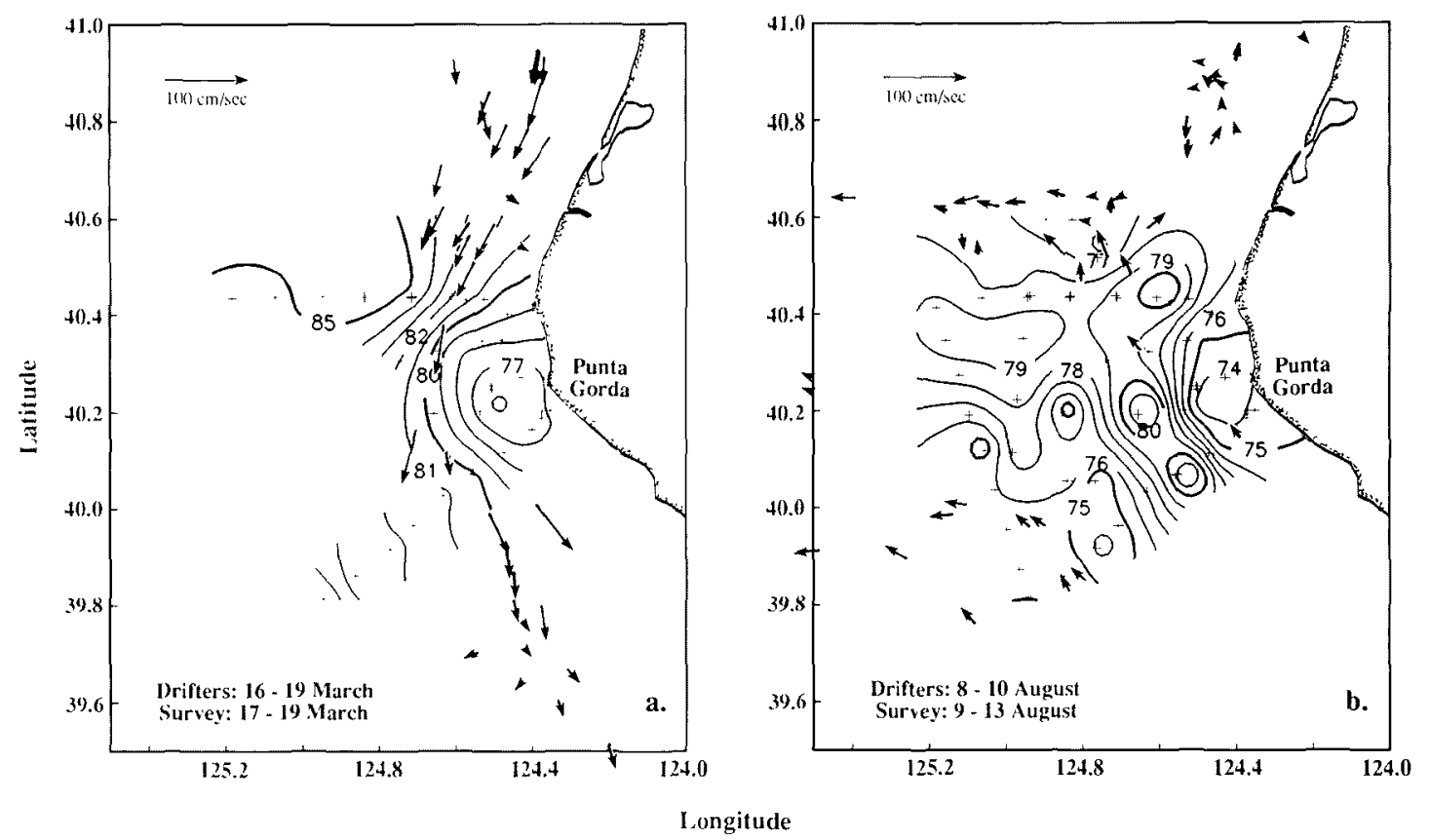

Fig. 5: Surface dynamic topography for (a) March and (b) August 1987 small-scale surveys, with drifter tracks for the same time superimposed. The contour interval is $1 \mathrm{dyn} . \mathrm{cm}$. Vectors represent daily average surface $(1 \mathrm{~m}$ ) drifter velocities plotted at the drifter location for the periods (a) March $16-19$ and (b) August 8-10.

days in order to obtain coverage of the area, the measurement periods were nearly coincident, and the evolution of the flow field was slow enough that the velocities implied by the two techniques should be comparable.

During the March survey, the drifters moved southward alongshore with a rather uniform velocity of about $50 \mathrm{~cm} / \mathrm{s}$. Although some offshore deflection occurred around the dynamic low found just off the southern edge of the Cape, the aggregate of drifter paths, shown in Fig. 6a, indicates unidirectional, alongshelf flow around the Cape. In contrast, the August survey was characterized by a more complex pattern of surface flow: the dynamic low was still present, and in the same location, but there was a narrow ridge of high dynamic height just offshore. accompanied by convergence and offshore flow extending to the western edge of the survey region. This pattern is also evident in the drifter tracklines for August (Fig. 6b).

\section{Remote Sensing}

Satellite images of sea-surface temperature (SST) were acquired regularly during the course of the pilot experiment. These SST images may be grouped into two categories: those with a large cold water plume off Cape Mendocino and those where the coldest temperatures are confined to the shelf and slope. Images from the two survey periods (Fig. 7, p. 9) are compared with the late May image in Fig. 1.

The expected pattern of SST during an upwelling event is shown in the image from March 24 (Fig. 7a): coldest water at the coast, with enhanced upwelling south of Cape Blanco, Cape Mendocino, and Point Arena. During CODE, persistent small-scale features of SST patterns south of Pt. Arena were shown by Winant et al. (1989) to result from supercritical flow in the atmosphere near Point Arena. Similar upwelling patterns south of Cape Mendocino indicate that the same wind stress patterns may, at times, be found there.

The other SST pattern commonly observed is characterized by a large plume of cold water extending offshore from the Cape. This pattern is associated with convergence in the shelf currents near the Cape, and, presumably, with offshore flow. The cold plume observed in the May 19 image (Fig. 1) is also associated with convergence in the wind field. However, similar SST structures are observed when the wind field is uniform around the Cape, for example in the image from August 1 (Fig. 7b). It is probable, then, that convergent shelf flow is attributable to several factors, of which convergent flow in the atmospheric marine layer is only one.

\section{Summary}

The 1987 NCCCS pilot experiment observations illustrate the complexity of shelf flow near Cape Mendocino, a major promontory of the northern California coast. Currents and temperatures from either side of the Cape were not correlated, in general, and there was less coherence between currents along the shelf, and between currents and local winds, than expected from the CODE results. The 

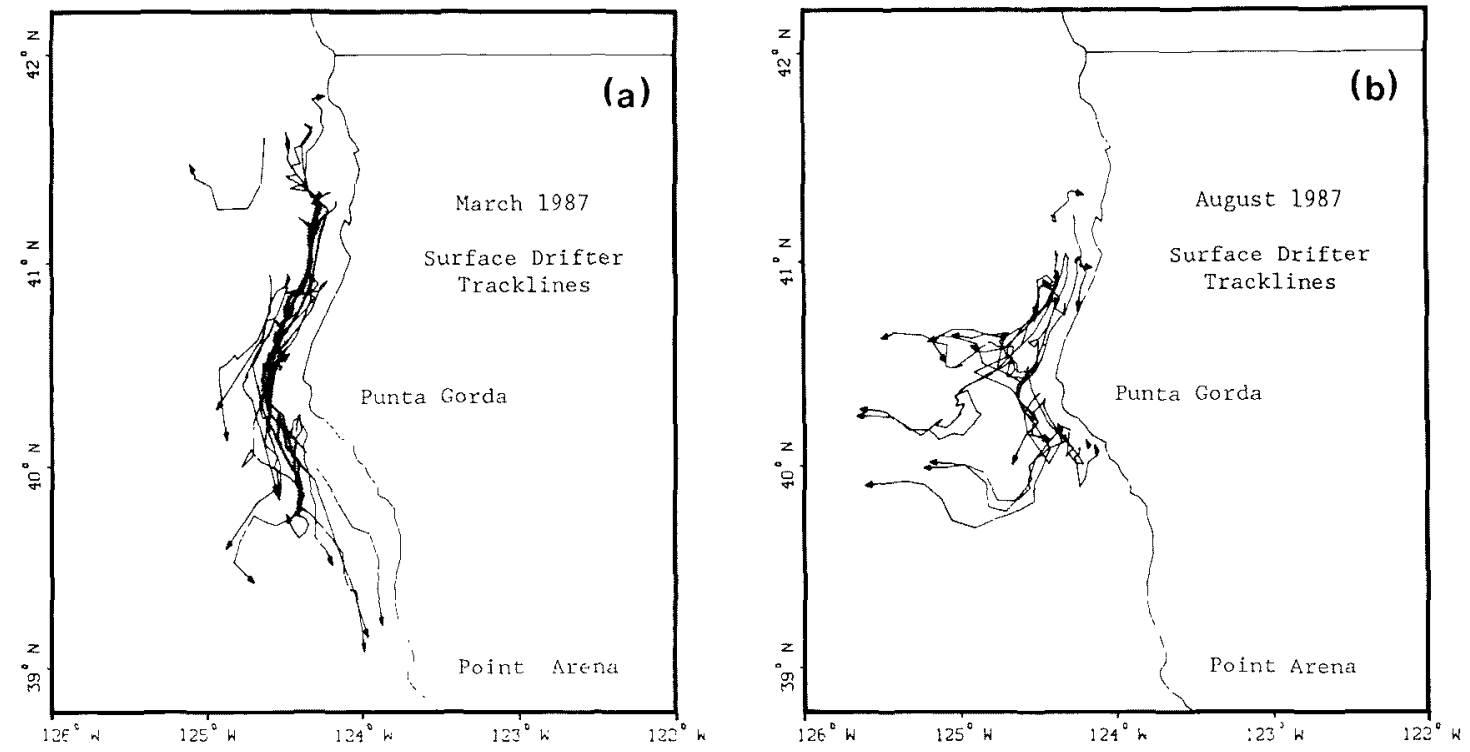

Fig. 6: Drifter tracklines for (a) the March 1987 and (b) the August 1987 surveys.

high alongshelf correlation observed within a coastal embayment during the CODE experiment contrasts markedly with the lack of correlation around Cape Mendocino during NCCCS.

Shelf currents from the pilot experiment were divided into two patterns. The first pattern, consisting of continuous, generally southward flow around the Cape, is evident during the March survey. With this pattern. coldest surface temperatures are confined to the shelf and slope. The second pattern is characterized by convergence and offshore flow at the Cape, as is evident during the August survey, as well as most of April and May. Surface temperatures during these periods show a cold plume extending 200-300 km west of the Cape. In both surveys, a local dynamic low persists on the southern side of the cape.

These observations raise several questions about the origin of convergent shelf flow and its relationship to winds, upwelling, the California Current system, topography and shelf waves. How much of the convergent shelf circulation results directly from atmospheric forcing? Some of the convergence in shelf currents is attributable to variations in the larger-scale winds about the Cape. However, there are extended periods of convergence on the shelf accompanied by uniformly equatorward winds. During the pilot experiment. a pronounced upwelling center typically was found off the south side of Cape Mendocino. Currents in this region were generally poleward, not equatorward as might be inferred from the classical upwelling pattern. How is upwelling related to convergence of the shelf flow? During CODE it was observed that shelf flow was poleward when the winds ceased, suggesting a large scale pressure gradient. Does the same gradient drive the poleward flow south of Cape Mendocino, or is poleward flow a result of the upwelling center there? Are other mechanisms important? Although the California Current is the primary source of open ocean energy along the west coast of the United States, the continuity of that current and the extent to which it impinges on the shelf are not known. Does the California Current influence, or even at times constitute, the shelf flow north of Cape Mendocino? Are the upwelling center and poleward flow found south of the Cape actually caused by separation of the large-scale current from the coast at the Cape? Turning the question around, rather than the California Current causing offshore flow at capes, are meanders and eddies of the California Current perhaps induced by offshore shelf flow generated by other mechanisms? These last two suggestions are not mutually exclusive; it may be that a subtle interaction between wind-driven shelf convergence and variations in the structure of open ocean currents is responsible for the complexity and variety of the observed circulation patterns.

\section{Acknowledgements}

The Northern California Coastal Circulation Study is supported by the Pacific OCS office of the Minerals Management Service of the U.S. Department of the Interior, under contract 14-12-0001-30312. This project could not have been accomplished successfully without the support and encouragement of Mr. Sigurd Larson, the MMS COTR. Dr. John Largier is partially funded by a grant from the California Department of Boating and Waterways. Special thanks are due to the Captain of the R/V Glorita, Thomas Crawford, and his capable crew, for their determination to complete the surveys and mooring work despite strong winds and heavy seas.

\section{References}

Halliwell, G.R.. Jr. and J.S. Allen, 1987: Wave Number-Frequency Domain Properties of Coastal Sea Level Response to Alongshore Wind Stress along the West Coast of North America, 1980-1984. J. Geophys. Res., 92(C11), 11,76111.788.

Kelly, K.A., 1985: The influence of winds and topography on the sea-surface temperature patterns over the northern California slope. J. Geophys. Res., 90, 11,783-11,798.

[ Please Turn to Page 64 ] 
as alleging "that many scientists concerned about pollution, ozone depletion and global warming are motivated more by pecuniary interests than by altruistic desires to advance the common good." This allegation. the editorial says, "may be dismissed as extremist or irrational. unworthy of reaction." The tone of the editorial is that the scientist is above such suspicion.

If the Chronicle article does suggest that greenhouse scientists are motivated by pecuniary rather than altruistic interests, then it is, of course, wrong. But its error is not because scientists are morally superior, but because it twice misunderstands the motivation of scientists: few, if any, world-class scientists entered science to get rich, and relatively few entered the physical sciences to advance the common good.
A subtle discussion of their actual motivation is in the same issue of Oceanography (Nov. 89. H. Stommel, "Why We are Oceanographers"). Scientists become scientists to discover things about the world around us. The currency of science is not dollars, but fame for discovery, and that fame increases with the unexpectedness and generality of the discovery. In seeking fame, scientists are not morally superior to nonscientists. There are many examples of how the desire for fame corrupted a scientist's actions, from the subconscious rejection of non-confirming data to the brutal discrediting of rival theories.

Predictions of the effects of greenhouse warming are part of the scientific fame of those making the predictions. When the predictors seek to influence public policy with advice based on their predictions, a citizen is only being prudent in requiring skeptical review.

Cyril Galvin. Principal Coastal Engineer Box 623. Springfield. Virginia 22150

My comments about the Chronicle article were prompted mostly by its summary statement. "we are being peddled protection from non-existent hazards." To me, this seems an extreme and irrational view, given the mounting evidence for ozone depletion and global warming and the environmental hazards they portend. Far from being exempt from public scrutiny, scientists face an added obligation to sift arailable evidence and interpret it responsibly for a critical public. $-D A B \square$

\section{Convergent Shelf Flow at Cape Mendocino}

[ Continled from Page 11 ]

\author{
Magnell, B.A.. C.D. Winant. N.A. Bray, J.F. \\ Borchardt. C.L. Greengrove, C.E. Dor- \\ man. R.L. Bernstein. 1989: The Northern \\ California coastal Circulation Study: \\ Results of the Pilot Program. Prepared for \\ Department of Interior, Minerals Man- \\ agement Service. EG\&G WASC Oceano- \\ graphic Services Report No. NCCCS-89-2. \\ Waltham, Massachusetts. $270 \mathrm{pp}$. \\ Magnell, B.A., J.F. Borchardt, C.L. Greengrove, J.B. \\ Andrews. C.D. Winant, N.A. Bray. C.E. Dor- \\ man, and R.L. Bernstein, 1988: Northern
}

California coustal Circulation Study Data Report No. 1: Pilot Measurement Program, March-August 1987. Prepared for Department of Interior, Minerals Management Service. EG\&G WASC Oceanographic Services Report No. NCCCS-89-9, Waltham. Massachuseuts. $268 \mathrm{pp}$.

Rosenfeld, L.K. and R.C. Beardsley, 1987: Barotropic Semidiurnal Tidal Currents off Northem California During CODE. J. Geophys Res.. 92(C2). 1721-1732.
Winant, C.D., R.C. Beardsley, and R.E. Davis, 1987: Moored Wind. Temperature, and Current $\mathrm{Ob}-$ servations made During Coastal Ocean Dynamics Experiments 1 and 2 over the Northern California Continental Shelf and Upper Slope. J. Geophys. Res., 92(C2). 1569-1604.

Winant, C.D.. C.E. Dorman, C.A. Friehe, and R.C. Beardsley, 1989: The Marine Layer off Northem Californa: An example of supercritical channel flow. $J$. Atmos. Sci.. 45, 3588-3605. $\square$

\section{Physical Oceanography in the 1990s}

[ Continued from Page 52 ]

In the late $1980 \mathrm{~s}$, as a cure for perceived lagging productivity in science. the federal government began to push multi- and interdisciplinary research. By tradition and its very nature, ocean science has always been at least multidisciplinary and in many cases interdisciplinary. The hard questions concerning global climate change in the next decade will require advances in areas of common need, such as moored technology for chemistry and biology, modeling as an integrator of fields, and a fuller appreciation of the wealth of intellectual problems in ocean science.

New tools for measuring currents and improved models capable of handling the messy combination of processes at work in the coastal ocean may make the 1990s the decade of the coastal oceanographer. Again. some of the growth in this area will be fed by a community more closely tied to socie- tal needs in the coastal domain. Finally, to match the observations from space. the hydrographic efforts, and the models, it is possible to forsee a global in situ ocean measurement network based on very-longterm site moorings, global drifter and float networks, and even perhaps the first "Slocums," as Stommel suggested. The latter will bring ocean science closer to meteorology, but not to the point, one hopes, where scientists no longer go to sea. 